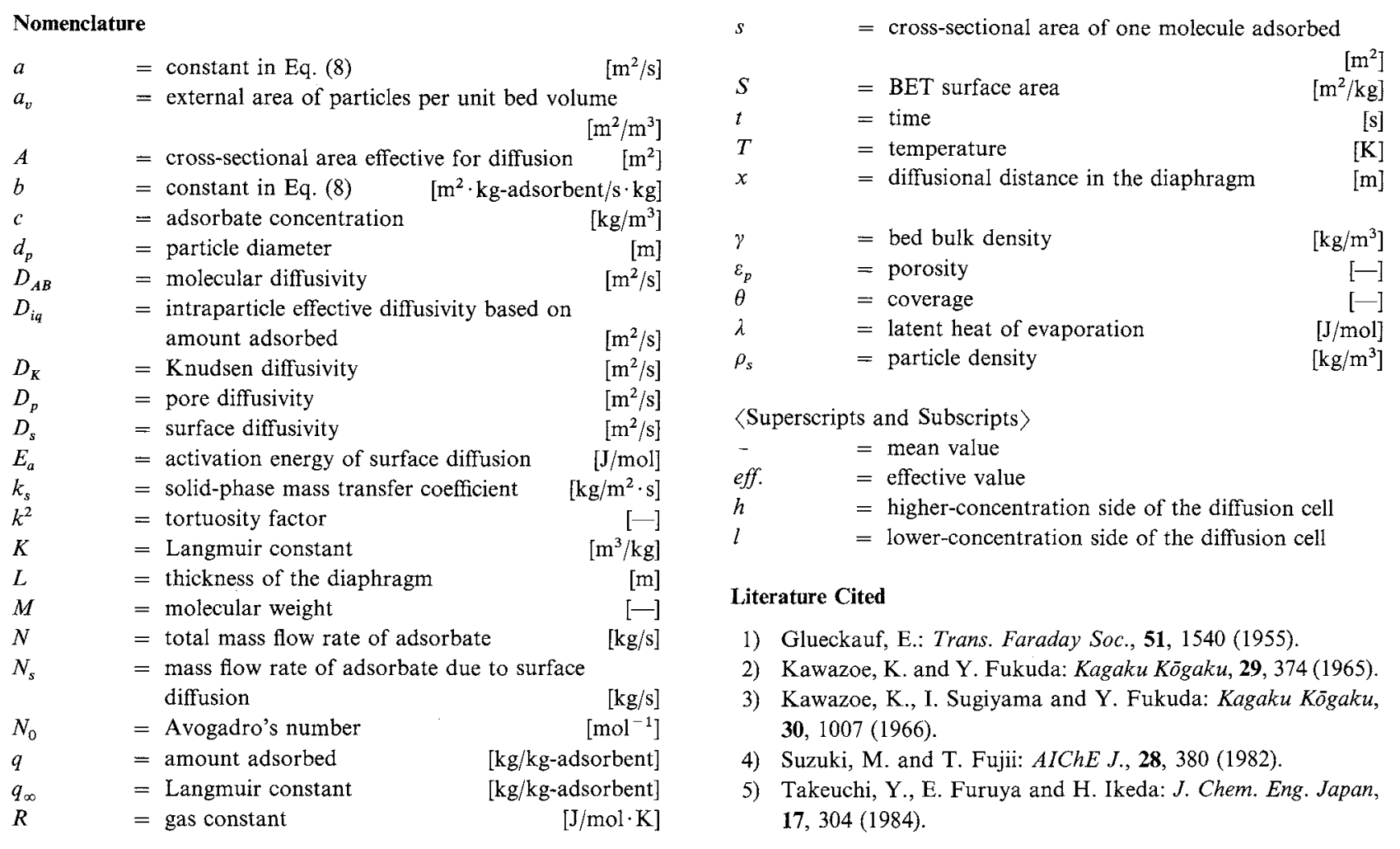

\title{
EFFECTS OF NATURAL CONVECTION AND FLUID MIXING ON MASS TRANSFER BETWEEN PARTICLES AND FLUID IN PACKED BEDS
}

KENJI KUBO

Department of Industrial Chemistry, Osaka Prefectural Technical College, Neyagawa 572

HARUO HIKITA

Department of Chemical Engineering, University of Osaka Prefecture, Sakai 591

\author{
Key Words: Mass Transfer, Dissolution, Packed Bed, Natural Convection, Forced Convection, Fluid \\ Mixing
}

Mass transfer between solid particles and a liquid flowing very slowly in packed beds is an important factor in determining the controlling rates in many mass transfer operations, such as ion exchange, adsorption, chromatography and catalytic processes. At very low flow rates, mass transfer in packed beds may be affected by natural convection and by axial fluid mixing. However, very few studies have been reported in the literature on the effects of these factors on the mass transfer rate. In the present work these problems

Received June 18,1984 . Correspondence concerning this article should be addressed to K. Kubo. were studied.

\section{Theory}

Consider dissolution from the surface of solid spherical particles in a packed bed into a liquid flowing very slowly. When the axial fluid mixing in the packed beds is assumed to be described by the sidemixing model proposed in a previous paper, ${ }^{5)}$ mass balances over a differential length of the packed bed yield the following equations in dimensionless form:

$$
(1-\beta) \frac{\partial C_{1}}{\partial \tau}=-\frac{\partial C_{1}}{\partial \xi}+M\left(C_{2}-C_{1}\right)
$$




$$
\beta \frac{\partial C_{2}}{\partial \tau}=M\left(C_{1}-C_{2}\right)+N_{L}\left(C_{s}-C_{2}\right)
$$

where

$$
M=L / u R_{M}
$$

and

$$
N_{L}=k_{L} a_{t} L / u
$$

The boundary conditions for Eqs. (1) and (2) are

$$
\begin{array}{ll}
\xi=0 ; & C_{1}=C^{\text {in }}=0 \\
\xi=1 ; & C_{1}=C^{\text {out }}
\end{array}
$$

Under steady-state conditions, solution of Eqs. (1) and (2) gives the value of $C^{\text {out }}$, the solute concentration at the outlet of the packed bed, and is expressed as

$$
C^{\text {out }}=C_{s}\left[1-e^{-M N_{L} /\left(M+N_{L}\right)}\right]
$$

When it is assumed that no fluid mixing exists in the packed bed, the outlet solute concentration $C^{\text {out }}$ under steady-state conditions can be given by

$$
C^{\text {out }}=C_{s}\left(1-e^{-\hat{N}_{L}}\right)
$$

where

$$
\hat{N}_{L}=\hat{k}_{L} a_{t} L / u
$$

Equating Eq. (7) and Eq. (8), the relationship between $\hat{N}_{L}$ and $N_{L}$ is obtained as

$$
\frac{1}{\hat{N}_{L}}=\frac{1}{N_{L}}+\frac{1}{M}
$$

from which the relationship between $\hat{k}_{L}$ and $k_{L}$ is expressed as

$$
\frac{1}{\hat{k}_{L}}=\frac{1}{k_{L}}+R_{M} a_{t}
$$

Therefore, when the values of $R_{M}$ and $a_{t}$ are known, the values of the true mass transfer coefficient $k_{L}$ can be determined from the values of the apparent mass transfer coefficient $\hat{k}_{L}$.

In the previous paper, ${ }^{3)}$ mass transfer between solid particles in a packed bed and a flowing fluid in the laminar flow region, where both forced and natural convection are important, was analyzed theoretically on the basis of the free-surface model proposed by Happel. ${ }^{2)}$ According to this model, the average Sherwood number is given by

$$
S h=\frac{k_{L} d_{p}}{D}=\frac{\gamma}{1-\gamma} \int_{0}^{\pi} \frac{\eta_{b} \sin \theta}{I_{1}\left(\eta_{b}\right)} d \theta
$$

Here $\gamma$ and $\eta_{b}$ are dimensionless parameters defined by

$$
\gamma=(1-\varepsilon)^{1 / 3}
$$

and

$$
\eta_{b}=\left(\frac{d_{p}^{2}}{16 D}\right)^{1 / 3}\left(\frac{1-\gamma}{\gamma}\right) \frac{\sqrt{\alpha} \sin ^{1 / 2} \theta}{\left(\int_{0}^{\theta} \sqrt{\alpha} \sin ^{3 / 2} \theta d \theta\right)^{1 / 3}}
$$

Further, $\alpha$ in Eq. (14) can be obtained from the following equation:

$$
\begin{aligned}
\frac{d_{p}^{2} \alpha}{D \sin \theta}= & 6\left(\frac{1-\gamma^{5}}{W}\right) P e \\
& +0.161\left(\frac{1-\gamma}{\gamma}\right) R a \frac{\eta_{b}^{2} I_{2}\left(\eta_{b}\right)-6 I_{4}\left(\eta_{b}\right)}{\eta_{b}^{3} I_{1}\left(\eta_{b}\right)}
\end{aligned}
$$

where

$$
\begin{aligned}
& W=2-3 \gamma+3 \gamma^{5}-2 \gamma^{6} \\
& P e=S c R e=d_{p} u / D \\
& R a=d_{p}^{3} \beta_{e} g\left(C_{s}-C_{0}\right) / v D
\end{aligned}
$$

Thus, Eq. (12) with Eqs. (13) to (18) gives the theoretical values of the average Sherwood number under conditions of combined forced and natural convection as a function of $P e, R a$ and $\gamma$ or $\varepsilon$. When $R a$ is zero, the situation corresponds to pure forcedconvection mass transfer in packed beds and Eq. (12) with Eqs. (14) and (15) leads to

$$
S h=1.25\left(\frac{1-\gamma^{5}}{W}\right)^{1 / 3} P e^{1 / 3}
$$

This equation agrees with that derived by Pfeffer. ${ }^{6)}$

\section{Experimental Apparatus and Procedure}

The apparatus and experimental procedure employed were similar to those used by Williamson et $a l .{ }^{7)}$ The packed column was an $8.0-\mathrm{cm}$ inside diameter, $85.5 \mathrm{~cm}$-high meta-acrylic resin tube. The inlet flow of the liquid was downflow through a packed bed of benzoic acid cylinders sandwiched between two layers of inert ceramic cylinders identical with the active benzoic acid cylinders. The 1.5 to $3.0 \mathrm{~cm}$ layer of active cylinders was located $7.0 \mathrm{~cm}$ from the bottom of the column. The active cylinders were pressed from reagent-grade benzoic acid in a polished steel mould by applying a pressure of about $200 \mathrm{MPa}$. The cylinders were $1.29 \mathrm{~cm}$ in outside diameter and $1.29 \mathrm{~cm}$ in height.

The liquid used was pure distilled water at $25^{\circ} \mathrm{C}$ and its flow rate was determined by collecting and weighing the outlet liquid for a measured time. After the system reached steady state, the outlet liquid was sampled and analyzed for benzoic acid by titration with $10 \mathrm{~mol} / \mathrm{m}^{3} \mathrm{NaOH}$ solution using phenolphthalein as indicator. The precision of analysis was about $0.1 \%$. Thus the error in the concentration driving force was less than $1 \%$.

The values of the apparent mass transfer coefficient $\hat{k}_{L}$ were calculated from the following equation: 


$$
\hat{k}_{L}=\left(\frac{Q}{a_{t}}\right) \ln \frac{C_{s}-C^{i n}}{C_{s}-C^{\text {out }}}
$$

\section{Results and Discussion}

The present experimental results, shown as a relationship between apparent Sherwood number $\widehat{S h}$ and Reynolds number Re, were compared with previous data ${ }^{1,4,7,8)}$ on the dissolution of benzoic acid particles into water flowing slowly under downflow conditions and also with the theoretical line representing Eq. (19) derived by Pfeffer $^{6}$ for pure forced convection. For a non-spherical particle, the diameter of a sphere having the same surface area was used as the value of $d_{p}$. At higher Reynolds numbers $(R e>10)$, agreement between the present and previous data was fairly good and the data points were in good agreement with the theoretical line representing Eq. (19). At lower Reynolds numbers $(R e<10)$, where the data points scattered considerably, the present data agreed well with the data of Dryden et al., ${ }^{1)}$ but were somewhat higher than the other previous data. Further, the present data deviated upward from the theoretical line representing Eq. (19) with increasing $R e$. This deviation might be due to the effects of natural convection and axial fluid mixing in the packed bed.

In Fig. 1 the present experimental results are shown as a logarithmic plot of the Sherwood number $\widehat{S h}$ or $S h$ vs. the Peclet number $P e$ and compared with the theoretical lines. In the case of dissolution of benzoic acid particles into water flowing slowly under downflow conditions, the natural convection currents have the same direction as the forced convection flow and increase the dissolution rates of benzoic acid. The dashed line in Fig. 1 shows Eq. (19), which is valid for pure forced convection, while the solid line represents Eq. (12) with Eqs. (13) to (18), which was derived for combined forced and natural convection. The difference between the solid and dashed lines represents the effect of natural convection on the Sherwood number, and this effect becomes quite pronounced at lower values of $P e$. At higher values of $P e$ above $10^{4}$, the solid line practically agrees with the dashed line and the open circles representing the measured values of $\widehat{S h}$ are in good agreement with these theoretical lines. At lower values of $\mathrm{Pe}$ below $10^{4}$, the data points (open circles) lie relatively above the dashed line, but fall considerably below the solid line. The difference between the solid line and the data points may be attributed to the effect of axial fluid mixing in the packed bed. The solid circles in Fig. 1 represent $S h$ values based on the $k_{L}$ values calculated from the $\hat{k}_{L}$ values by using Eq. (11) and the empirical correlation for the side-mixing resistance $R_{M}$ presented in the previous paper. ${ }^{5)}$ As can be seen in the figure, the data

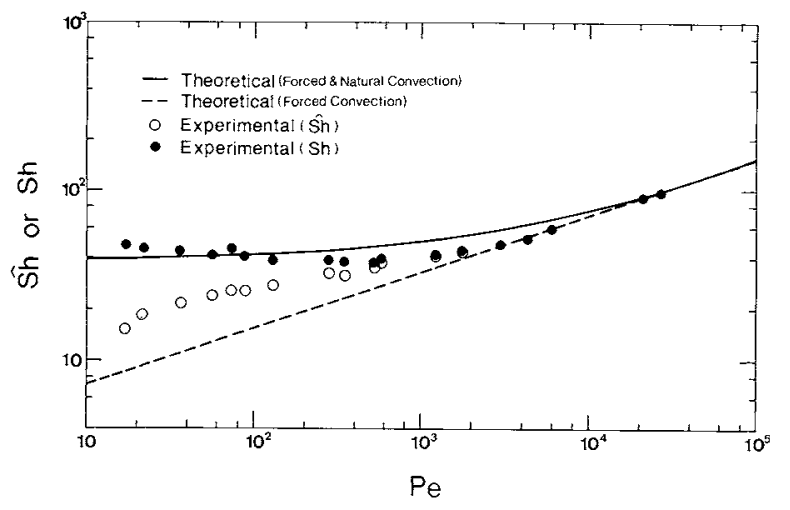

Fig. 1. Comparison of present experimental data with theoretical predictions.

points (solid circles) which were corrected for the effect of axial fluid mixing are in fairly good agreement with the solid line, although the experimental data are somewhat higher or lower than the theoretical line.

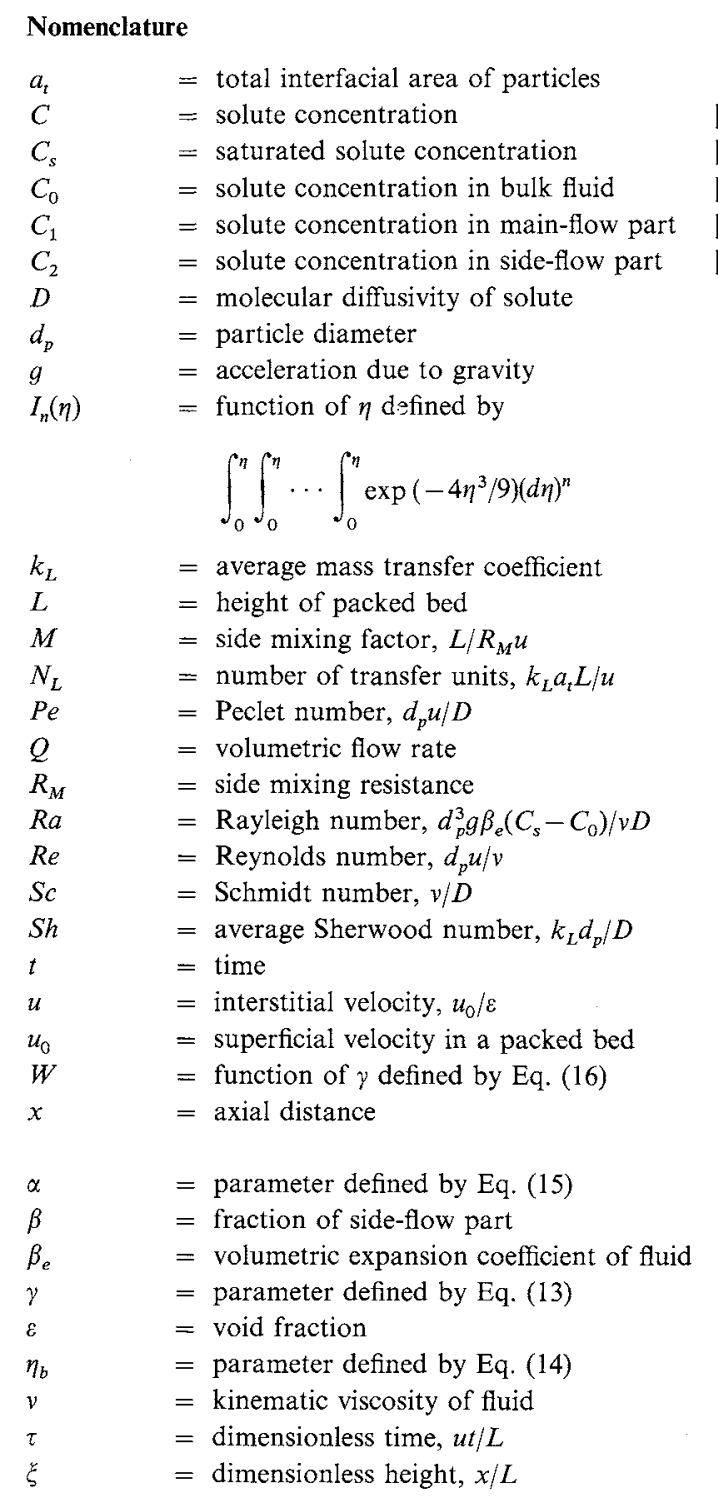

$\left[\mathrm{m}^{2}\right]$ $\left[\mathrm{mol} / \mathrm{m}^{3}\right]$ $\left[\mathrm{mol} / \mathrm{m}^{3}\right]$ $\left[\mathrm{mol} / \mathrm{m}^{3}\right]$ $\left[\mathrm{mol} / \mathrm{m}^{3}\right]$ $\left[\mathrm{mol} / \mathrm{m}^{3}\right]$ $\left[\mathrm{m}^{2} / \mathrm{s}\right]$ [m] $\left[\mathrm{m} / \mathrm{s}^{2}\right]$

$$
\begin{array}{r}
{[-]} \\
{[\mathrm{m} / \mathrm{s}]} \\
{[\mathrm{m}]} \\
{[-]} \\
{[-]} \\
{[-]} \\
{\left[\mathrm{m}^{3} / \mathrm{s}\right]} \\
{[\mathrm{s}]} \\
{[-]} \\
{[-]} \\
{[-]} \\
{[-]} \\
{[\mathrm{s}]} \\
{[\mathrm{m} / \mathrm{s}]} \\
{[\mathrm{m} / \mathrm{s}]} \\
{[-]} \\
{[\mathrm{m}]} \\
{[-]} \\
{[-]} \\
{[-]} \\
{[-]} \\
{[-]} \\
{[-]} \\
{[-]} \\
{\left[\mathrm{m}^{2} / \mathrm{s}\right]} \\
{[-]} \\
{[-]}
\end{array}
$$




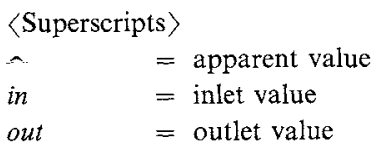

Literature Cited

1) Dryden, C. E., D. A. Strang and A. E. Withrow: Chem. Eng. Progr., 49, 191 (1953).

2) Happel, J.: AIChE J., 4, 197 (1958).

3) Hikita, H., K. Ishimi and K. Kubo: Chem. Eng. Commun., 17, 239 (1982).
4) Kataoka, T., H. Yoshida and K. Ueyama: J. Chem. Eng. Japan, 5, 132 (1972).

5) Kubo, K., T. Aratani and A. Mishima: Kagaku Kogaku Ronbunshu, 7, 304 (1981).

6) Pfeffer, R.: Ind. Eng. Chem. Fundam., 3, 380 (1964).

7) Williamson, J. E., K. E. Bazaire and C. J. Geankoplis: Ind. Eng. Chem. Fundam., 2, 126 (1963).

8) Wilson, E. J. and C. J. Geankoplis: Ind. Eng. Chem. Fundam., $5,9(1966)$.

\title{
MOISTURE PROFILE OF UNGLAZED ALUMINA-BASED CERAMIC ON CONVECTION DRYING
}

\author{
HIRONOBU IMAKOMA, MORIO OKAZAKI AND RYOZO TOEI \\ Department of Chemical Engineering, Kyoto University, Kyoto 606
}

Key Words: Convection Drying, Nonhygroscopic Material, Drying Model, Moisture Profile, Water Movement Model

\section{Introduction}

To express the water movement in an unsaturated porous body, we have proposed a modified KozenyCarman equation originating from the capillary action. ${ }^{3,7)}$ This equation was applied to the movement of condensed water in fine capillaries in an adsorptive porous body and it was found that the Kozeny constant varies inversely with the ratio of the amount of condensed water to the total moisture content: $K_{c} \propto X^{*} / X_{1}{ }^{8)}$ This relation was confirmed by comparing the experimental drying data of an activated alumina rod with the calculated value. ${ }^{9)}$

The object of this study is to confirm whether this simple relation can be applied to the movement of liquid water in fine capillaries in a non-hygroscopic porous body on drying, and to simulate the drying process using this water movement model and the drying model proposed by the authors. ${ }^{7)}$

\section{Experimental Results}

The model material employed is an unglazed alumina-based ceramic. The experimental details are described in the previous study. ${ }^{6}$ Figure 1 indicates the cumulative curves of the pore volume and the surface area determined by the mercury penetration technique. The moisture content, $X$, can be calculated

Received Octobes 3, 1984. Correspondence concerning this article should be addressed to H. Imakoma. by the equation $X=\rho_{l}\left(V_{t}-V\right)$, using the cumulative pore-volume distribution, $V$, in this figure.

Figures 2 and 3 illustrate the experimental results. As may be seen from Fig. 3, the drying process was isothermal during all the period of drying except $t<2 \mathrm{~h}$ in this experiment.

The critical moisture content was established during $5 \mathrm{~h}<t_{c}<6 \mathrm{~h}$ and the surface moisture content at this point $X_{c} / X^{*}$ was 0.22 (see Fig. 2). The value of $S_{c}$ determined from Fig. 1 is $1.09 \times 10^{2} \mathrm{~m}^{2} \cdot \mathrm{kg}^{-1}$. The value of $X_{c}$ is equivalent to the maximum amount of unremovable pendular water.

\section{Theory}

It was found that liquid water in a non-hygroscopic capillary porous body classified into two groups ${ }^{5}$ : funicular water capable of flowing in liquid state

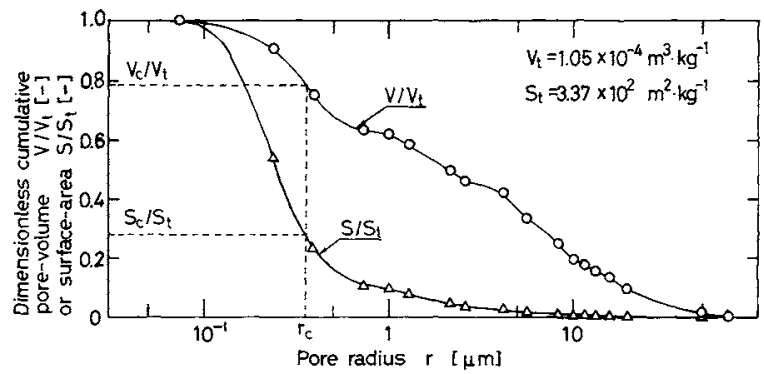

Fig. 1. Cumulative curves of pore volume and surface area. (Unglazed alumina-based ceramic.) 